\title{
Asthma diagnosis and treatment - 1025 . Prevalence of childhood asthma in small city of Iran: an ISAAC study
}

\author{
Shaghayegh Sadat Noorani Hassan Kiadeh", Mohammad Fereidouni, Amir Hossein Khozeime \\ From 2nd WAO International Scientific Conference (WISC 2012) \\ Hyderabad, India. 6-9 December 2012
}

\section{Background}

Asthma and other allergic disorders are common health problems around the world especially in children and have a negative impact on quality of life. Allergic diseases are one of the leading causes of school absence as well as reduction in children performance at school.

Epidemiologic Studies have shown that the prevalence of asthma and other allergic diseases have risen over the past decades. Many factors have been reported that contribute to this increase including genetic factors as well as environmental factors such as lifestyle, infections and diet.

Preventing and controlling allergic diseases require information about the Prevalence, risk factors and triggers which can be vary in different countries. The objective of this study was to determine the prevalence of asthma and other allergic diseases among 6-7 year old children in Birjand city.

\section{Methods}

In a cross-sectional survey in 2011, all school children age 6-7 years in Birjand city were evaluated based on ISAAC protocol. Persian version of ISAAC core questionnaire was completed by parents in total 3070 school children (M/F ratio $=0.88$ ) were participated in this study.

\section{Results}

The response rate was $91 \%$. The prevalence rate for Wheezing, physician diagnosis asthma, exercise wheeze, rhinitis and eczema was 15.5\%, 2.2\%, 3.2\%, 12.4\% and 8.2\% respectively. Except eczema, prevalence of other symptoms was higher in boys than girls but the differences were not significant compared with females.

Asthma, Allergy \& Immunology Research Center, Birjand University of Medical Sciences, Birjand, Iran

\section{Conclusions}

Our study shows that prevalence of rhinitis and wheezing is high among school children in Birjand city. Further studies should be performed to determine risk factors of allergic disorders in this area.

Published: 23 April 2013

doi:10.1186/1939-4551-6-S1-P24

Cite this article as: Kiadeh et al:: Asthma diagnosis and treatment 1025. Prevalence of childhood asthma in small city of Iran: an ISAAC study. World Allergy Organization Journal 2013 6(Suppl 1):P24.
Submit your next manuscript to BioMed Central and take full advantage of:

- Convenient online submission

- Thorough peer review

- No space constraints or color figure charges

- Immediate publication on acceptance

- Inclusion in PubMed, CAS, Scopus and Google Scholar

- Research which is freely available for redistribution

Submit your manuscript at www.biomedcentral.com/submit
() Biomed Central 